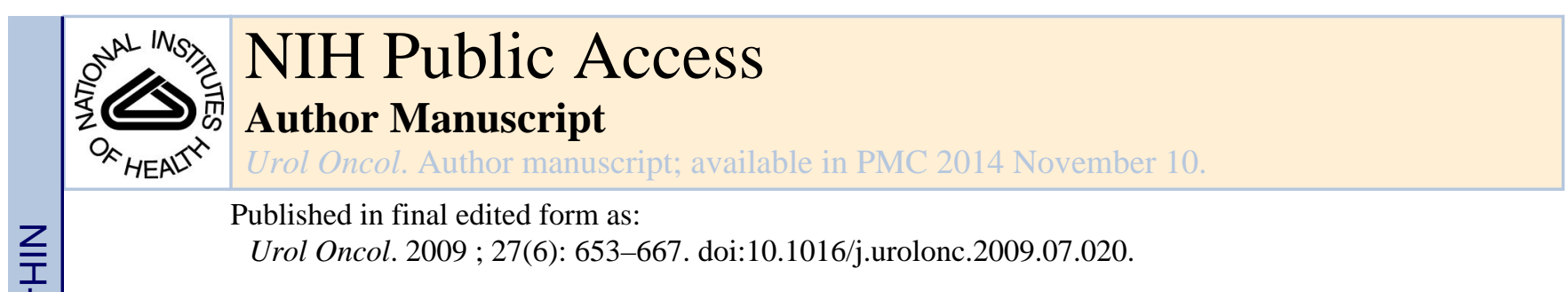

\title{
Bladder Cancer in the Elderly
}

Shahrokh F. Shariat, M.D., Ph.D. ${ }^{1}$, Matthew Milowsky, M.D. ${ }^{2}$, and Michael J. Droller, M.D. ${ }^{3}$

${ }^{1}$ Division of Urology, Sidney Kimmel Center for Prostate and Urologic Cancer, Memorial SloanKettering Cancer Center, New York, NY, USA

${ }^{2}$ Genitourinary Oncology Service, Sidney Kimmel Center for Prostate and Urologic Cancer, Memorial Sloan-Kettering Cancer Center, New York, NY, USA

${ }^{3}$ Department of Urology, The Mount Sinai Medical Center, New York, NY, USA

\section{Abstract}

Introduction-Age is now widely accepted as the greatest single risk factor for developing bladder cancer, and bladder cancer is considered as primarily a disease of the elderly. Because of the close link between age and incidence of bladder cancer, it can be expected that this disease will become an enormous challenge with the growth of an aging population in the years ahead.

Methods-Using MEDLINE, a search of the literature between January 1966 and July 2007 was performed to describe normative physiologic changes associated with aging, elucidate genetic and epigenetic alterations that associate aging with bladder cancer and its phenotypes; and to characterize how aging influences efficacies, risks, side effects and potential complications of the treatments needed for the various stages of bladder cancer..

Results-We discuss influence of aging on host physiology, genetic and epigenetic changes, environmental influences, and host factors in the development and treatment of bladder cancer. Treatments with intravesical Bacille Calmette Guerin, radical cystectomy, and perioperative chemotherapy are less well tolerated and have poorer response in elderly patients compared to their younger counterparts. Elderly patients face both clinical and broader institutional barriers to appropriate treatment and may receive less aggressive treatment and sub-therapeutic dosing. However, when appropriately selected, elderly patients tolerate and respond well to cancer treatments.

Conclusions-The decision to undergo treatment for cancer is a tradeoff between loss of function and/or independence and extension of life which is complicated by a host of concomitant issues such as co-morbid medical conditions, functional declines and "frailty", family dynamics, and social and psychological issues. Chronological age should not preclude definitive surgical therapy. It is imperative that healthcare practitioners and researchers from disparate disciplines collectively focus efforts towards gaining a better understanding of what the consequences of bladder cancer and its treatments are for older adults and how to appropriately meet the multifaceted medical and psychosocial needs of this growing population.

Address correspondence to: Michael J. Droller, M.D. Katherine and Clifford Goldsmith Professor of Urology Professor of Oncology Department of Urology The Mount Sinai Medical Center 1 Gustav Levy Place, Box 1272 New York, NY 10029 Phone (212)

241-8711 Fax (212) 876-3246 michael.droller@ mountsinai.org. 


\section{Keywords}

immunotherapy; age; recurrence; survival; bladder cancer; prognosis; radical cystectomy; urothelial carcinoma; chemotherapy; elderly

\section{Introduction}

Men and women aged 65 years and older represent approximately $12 \%$ (36.8 million) of the US population, a number expected to double by the year 2030. ${ }^{1-9}$ Data from the National Cancer Institute Surveillance, Epidemiology, and End Results (SEER) program for the most recent five year period (1998-2002) indicate that $56 \%$ of newly diagnosed cancers and $71 \%$ of cancer deaths occur in individuals who are 65 years and older. ${ }^{10}$ Regarding increase in life expectancy, the fastest growing segment of the population is the 85 years and older; this age group is projected to increase in number from 3.7 million in 1996, to 5.7 million in 2010, and to 18.2 million by $2050 .^{1}$

Age is now widely accepted as the greatest single risk factor for developing cancer, and cancer is considered as primarily a disease of the elderly. Approximately $60 \%$ of all incident malignancies in the US occur in adults aged $\searrow 65$ years; $16 \%$ of those aged $\ 65$ years have a history of cancer. ${ }^{5,8,9}$ Although cancer is the second leading cause of death among men and women aged $\succ 65$ years,, 8 many older adults are surviving cancer. In the US alone, it is estimated that 6.5 million of the 10.8 million cancer survivors are aged $\succeq 65$ years, with those $\geq 85$ years comprising $15 \%$ of this 6.5 million. Approximately $43 \%$ of these elderly men and women with cancer survive over 10 years and approximately $17 \%$ survive over 20 years from the time of their initial diagnosis. ${ }^{1,5,8}$ Because of the close link between age and incidence of cancer, it can be expected that cancer will become an enormous challenge with the growth of our aging population in the years ahead.

These cancer and aging trends are a major public health challenge that healthcare professionals will face in caring for this growing population. Unfortunately, evidence-based practice guidelines regarding the short-term and long-term management of urothelial carcinoma of the bladder (UCB) are sparse for this group. Moreover, it is inappropriate to extrapolate from studies on younger populations because older adults are physiologically, psychologically, and socially different from younger adults. ${ }^{11}$ For many older adults, cancer appears to be joining the ranks of other age-related chronic diseases, but the post-treatment burden of the disease (eg, loss of physical function, permanent disability, fatigue, insomnia, depression, anxiety, and economic devastation) is relatively unknown or at best poorly defined in this growing population. ${ }^{9}$

Several theories have been proposed to explain the interactions between carcinogenesis in general and the aging process. First, as individuals' age, they experience increasing exposure to carcinogens and the potential accumulation of cellular events that can lead to neoplastic transformation. Second, environmental exposure to carcinogens occurs cumulatively over time (particularly with cigarette smoking and with exposure to carcinogens in the workplace and/or in highly polluted living conditions). Third, the existence of a lag time between these exposures, the accumulation of cellular events, and the clinical expression of malignancy 
may account for the first appearance of bladder cancer in an older population. Also potentially contributing to this association is the increasingly prolonged contact of carcinogen-containing urine with the urothelium with aging, particularly in men with enlarged prostates and the development of increasing urine residuals with increased concentration of urinary contents. Of additional importance may be the decreased ability to detoxify potential carcinogens as the result of organ system deterioration with aging.

In recent years, there has been a small but steadily growing recognition that the link between aging and cancer is more complex than the simple passage of time to which age-dependence of cancer has traditionally been ascribed. Research on changes in the growth regulatory function of genes and proteins with advancing age and cancer has led to a better understanding of biological relationships between cancer development and aging and has introduced new possibilities for intervention. ${ }^{12}$ Certain genes may be activated while others may be suppressed with advancing age. This can lead to an increase in the activation of oncogene activity, leading to the genesis of a cancer cell, or a decrease in tumor-suppressor gene activity with inability to suppress or clear an organ of transformed neoplastic cells. Further, an aged cell may have a decreased capacity for repair of mutations in its DNA. In UCB, multiple genes have been found to fulfill the roles of both oncogenes and tumorsuppressor genes. ${ }^{13-15}$ These may then be associated with the development of different types of UCB with individualized and distinctive intrinsic biologic potentials..$^{13,15}$

In considering UCB and aging, it is also important to consider the phenomenon of aging itself and how it affects both the function and the physiologic reserve of different organ systems that may be important not only in the development of different forms of UCB but also in their specific treatment. Miller has defined aging as "the process that converts healthy adults into frail ones with diminished reserves in most physiologic systems and an exponentially increasing vulnerability to disease and death". ${ }^{16}$ The vulnerability that accompanies this process can affect various organ systems in different ways. It can also increase a host's vulnerability to the carcinogenic process. The development of a cancer itself as well as the treatments required can then affect organ systems in which limitations in physiologic reserve make an individual even more vulnerable to the cancer as well as to the potential risks and side effects of its treatment. ${ }^{17,18}$

In this article, we discuss normative physiologic changes associated with aging. In addition, we review the molecular pathways linking age and cancer. Third, we review the literature regarding the risk factors that contribute to the vulnerability of individuals to develop UCB, and the ability to deliver various forms of treatment (for both non-muscle invasive and muscle-invasive bladder cancer) in the elderly population in the context of their overall physiologic function and reserve.

\section{Physiologic changes that occur with aging}

Nearly all organ systems show a progressive physiologic decline in function beginning at age 30. ${ }^{17,19,20}$ The degree and timeline of this decline vary among different individuals and organ systems. Although these changes are generally imperceptible over the years, they can be unmasked through various internal and external stressors. Furthermore, even without the 
presence of actual disease, aging itself results in a gradual, progressive loss in the biologic reserve necessary for the body to maintain physiologic homeostasis under stress. A decreased age-dependent physiologic reserve manifests itself in a decreased resilience and compromised recoverability when an organ-system is exposed to stressors. In addition, many elderly individuals have one or more chronic medical conditions. These can further decrease their organs' physiologic reserve and ability to respond to stress.

In the general geriatric population, functional status as a whole and of individual organ systems together with level of dependency have been found to predict survival. ${ }^{21}$ Loss of physical function with resultant disability occurs with age. Over $60 \%$ of individuals ages 65 to 74 years have some disability, $65 \%$ of individuals ages 75 to 79 years report disability, and $>76 \%$ of individuals aged 80 years report some disabling conditions. ${ }^{22}$ Weight loss and poor nutritional status are associated with poorer response to therapy and decreased survival. ${ }^{23,24}$ For the elderly with cancer, the oncologist must be able to stage not only the cancer but also to consider how a patient's functional and physiological status may affect the ability to tolerate and respond to treatment and its risks, potential complications, and side effects. These considerations as reviewed by Hurria, et al ${ }^{17}$ are summarized and expanded upon as follows.

For the cardiovascular system, for example, aging is accompanied by a decrease in cardiac output and maximal heart rate as well as prolonged recovery following exercise. ${ }^{17,19,20,25,26}$ Moreover, there is a decreased response to catecholamines with stress..$^{25,26}$ Depending upon obesity, heredity factors, nutrition, weight loss, diet, and racial differences, such changes may be increasingly accentuated over time. ${ }^{25,26}$

Similarly, the pulmonary system demonstrates a decreased response to hypoxemia and/or hypercapnia, an increased ventilation/perfusion mismatch, a decreased elasticity of the lung tissue, and a decreased forced expiratory volume with advancing age. ${ }^{17,19,20,27}$ These are further affected by earlier environmental exposure to substances that may lead to emphysema, asthma, and decreased pulmonary reserve. ${ }^{19,20}$

Changes in the endocrine system during aging include decreases in insulin-like growth factors, growth hormones and sex steroids, and increases in insulin, norepinephrine, parathyroid hormone, vasopressin and atrial natriuretic peptides. ${ }^{17,19,20,28-30}$ The effects of aging on target organ systems compound these changes, with consequent diminution in their optimal responsiveness to the functional effects of these hormones. ${ }^{30}$ Related issues of weight loss and poor nutritional status are associated with poorer response to therapy and decreased survival. ${ }^{23,24}$

Age-related changes in the neurologic system comprise neuronal loss, a decrease in brain weight, decreasing vision, loss in both high frequency and low frequency hearing, and alterations in taste and smell. ${ }^{17,19,20,31}$ Cognitive and memory impairment, dementia and depression are also prevalent in elderly patients. ${ }^{32,33}$ In studies where comprehensive geriatric assessments were conducted in elderly patients with cancer, as many as $25 \%$ to $50 \%$ of the subjects screened positive for cognitive abnormalities. ${ }^{34}$ All of these may be important when various forms of therapy for UCB are considered. 
Aging is also associated with dysregulated immune and inflammatory responses. ${ }^{17,19,20,35-38}$ Declining $\mathrm{T}$ cell function is the most significant and best-characterized feature of immunosenescence. ${ }^{27,35-38}$ The immune system is thought to play an important role in the development and progression of cancer. Weakening of individual components of this system is thought to compromise an individual's overall defense against the development and progression of cancer. Deterioration of the immune system with aging includes a decrease in thymic mass with concomitant decrease in subpopulations of lymphocytes that comprise the thymus, decreased production in thymic hormones, a general decrease in subpopulations of antigen-processing and effector lymphocytes, and a decrease in antibody response. ${ }^{35-38}$ This has been suggested to explain, at least in part, the increased vulnerability to the development of cancer as people age.

Renal and hepatic functions also decrease with aging. ${ }^{17,19,20}$ Liver volume decreases by $25-50 \%$ with a corresponding decrease in hepatic blood flow, decrease in liver perfusion, and a decrease in the ability to react to and metabolize exogenous substances such as carcinogens. ${ }^{39,40}$ Renal mass decreases by $25-30 \%$ over time, leading to a decreased number of functional nephrons. ${ }^{41,42}$ Glomerular filtration is decreased by approximately $1 \mathrm{ml} /$ minute per year after age 40 , and renal blood flow decreases by approximately $1 \%$ per year after age 50. ${ }^{41-43}$ Each of these may play a role not only in an increased vulnerability to the exposure and effects of potential carcinogens but also in an individual's ability to accept the risks and side effects of various types of treatment (e.g., radical cystectomy, systemic chemotherapy) and recover from potential complications of those treatments.

Interactions between the immune, neurologic and endocrine systems may be important in the general response to external challenges, maintenance of homeostasis, and in the development and progression of cancer. ${ }^{17,19,20}$ The various neuronal networks, the role of neurotransmitters, the "wiring" of organ systems through neuronal and endocrine function, and their interconnections through an intact cellular and humoral immune system with the production of various molecules to maintain the body's general homeostasis are undoubtedly affected in various ways by aging. Deterioration in this complex interconnected and interactive system may contribute to an increased vulnerability to cancer development and progression and altered response to treatment with age. Each of these changes independently and in aggregate can contribute to the overall well-being and performance status of an individual. Moreover, each can contribute to and be challenged when an individual develops cancer and undergoes treatment that further challenges these changes and in which side effects and complications may further compromise normal function and physiologic reserve.

In addition to such specific changes, it is estimated that $10-25 \%$ of individuals over age 65 can be characterized as being "frail". ${ }^{44-46}$ The definition of frailty has been proposed as "a state of age-related physiological vulnerability resulting from impaired homeostatic reserve and reduced capacity of the organism to withstand stress". ${ }^{46,47}$ The development of malignancy in this context not only underscores the occurrence of the malignancy through a possible predisposition occasioned by the vulnerability of various organ systems, but also the stressful situation physiologically that can potentially increase the vulnerability of the different organ systems by both cancer development and its treatment. Unfortunately, mechanisms underlying these interactions have not been well-defined or characterized. 
Moreover, treatments that may be required can further stress various organ systems both physiologically as well as pharmacologically through side effects and complications that may occur. Thus, individuals become increasingly vulnerable as they age to the development and effects of cancers and their treatments. ${ }^{17,19,20,45}$ The interactions among functional status, frailty, and cancer treatment deserve further investigation. For example, the impact of treatments on indicators of frailty, such as anorexia, weight loss, fatigue, inactivity, sarcopenia, osteopenia, and de-conditioning is needed so that older cancer patients can make informed choices regarding their treatment options. ${ }^{45}$

In considering these fundamental physiologic issues, additional emphasis has been placed upon "co-morbidities". ${ }^{17,19,20,48}$ In cancer biology and treatment, the term "comorbidity" is defined as a concurrent medical problem that is a competing source of morbidity or mortality in the setting of a developing malignancy. This is superimposed on the normal physiologic deterioration of various organ systems experienced with aging, but pertains specifically to a particular "morbid" process that can affect the function of one or more organs and influence their vulnerability to the risks, side-effects and potential complications of various treatments. Not only the number but also the complexities of such co-morbidities increase with age. ${ }^{49}$

The most common co-morbidities include hypertension, heart-related conditions, diabetes, obesity and arthritis. ${ }^{17}$ Various co-morbid conditions and the number of such conditions increase with age. Furthermore, the levels of severity of a particular co-morbidity also affect functional recovery following various treatments. Correspondingly, the impact of a particular co-morbidity can effect overall survival through basic recoverability following the effects of various treatments themselves as well as recoverability following the manifestation of treatment risks, side effects, and potential complications. Each of these in turn can affect mortality.

Patients with three or more co-morbid conditions have been found to have a four-fold increased risk of mortality compared to those who had no co-morbid conditions. ${ }^{50}$ Ironically, the potential impact of a new disease as a competing cause of mortality has been found to decrease with increasing age. ${ }^{51}$ This may be the manifestation of a statistical phenomenon since it is associated with a decrease in absolute projected life expectancy. Thus, a particular condition may decrease life expectancy in a younger individual by a longer period of time than in an older individual because the life expectancy of the older individual is less.

Additional considerations revolve around observations that normal physiologic changes that accompany aging can also cause changes in the pharmacokinetics and pharmacodynamics of cancer therapy. ${ }^{17,42,52}$ This introduces the further risk factor of "polypharmacy". Older individuals tend to require more medications because they have more "co-morbid" conditions than do younger individuals. Furthermore, older patients may be more vulnerable to adverse drug events than younger patients, not only because they use more medications but because they have experienced changes in pharmacokinetics and pharmacodynamics associated with changes in physiologic function and reserve with aging. ${ }^{17,42,52}$ These include age-related changes in gastrointestinal function, distribution of various drugs in 
different compartments and organ systems, increase in body fat (leading to slower metabolism of lipid-soluble drugs), decrease in total body water (leading to an increase of water-soluble drugs in plasma), decrease in lean body mass, decrease in serum albumin, and decrease in hemoglobin. ${ }^{17,42,52}$ In addition, renal clearance decreases, even if no elevation of blood urea nitrogen or creatinine is detected. ${ }^{42,52}$ This can effect clearance of medications and their metabolites and can be compounded by an age-related decrease in renal mass, functional nephrons, glomerular filtration, tubular secretion, and tubular reabsorption. Similarly, blood flow to the liver decreases with increasing age, liver volume shrinks, and metabolic enzymatic activity is reduced, all impacting hepatic metabolism. These changes, individually and in aggregate, may contribute to a change in the distribution of various medications and their metabolism.

The extent to which age-related physiologic changes affect disease progression, response to treatment, survivorship, and adverse effects in the elderly is unknown. These coexisting medical conditions can complicate prevention, diagnosis, efficacy of and extent of treatment offered, response to treatment, and post-treatment health. From a psychological standpoint, the gerontology literature reveals that many older adults perceive less control over their health, experience fewer emotional highs and lows, and adjust their expectations and attitudes regarding their current state of health and/ or ability to recover from adverse health events as they age. ${ }^{53,54}$ In addition, many elderly adults have had previous experience with health issues, multiple cancer diagnoses, and other life losses due to their position in the sequences of life. The extent to which life experiences influence current beliefs and attitudes warrants further consideration.

Of additional major importance in the care of elderly individuals with UCB and treatment planning in specific clinical situations are social factors such as the availability of a network to provide home care, socio-economic status, transportation, and living arrangements, such as assisted living. For example, therapeutic modalities requiring daily administration for a long period may be inappropriate for older patients who cannot mobilize transportation or the social, emotional, or psychological support necessary for this. Home care may also be compromised. Many surveillance and treatment strategies could result in a shift towards greater dependence if aggressive treatment is pursued. If the individual is in a setting with family support, the decision to undergo treatment could introduce issues of care-giving and dramatically change the family dynamics. Conversely, if an individual does not have a family support structure to help in dealing with cancer, he or she may believe that treatment might precipitate placement that might threaten their independence and lead them to reject this.

Finally, it is important to note that as we age we become more heterogeneous in terms of physical and psychosocial health as a result of our previous lifestyle, environmental exposure, and genetic composition. As a result, age should not be used as a proxy for health status and categorizing men and women aged $\succ 65$ years as one homogeneous group. ${ }^{55} \mathrm{In}$ the US, an elderly person is arbitrarily defined as someone aged 65 years for bureaucratic reasons. Many healthcare professionals make critical medical care decisions based on this artificial cutoff. New strategies are needed to assess the health status of older adults, which could include the use of comprehensive geriatric assessments and performance-based 
measures. ${ }^{56}$ Understanding within-group variations among older adults across the cancer control continuum requires more attention to be paid to variable aspects of physiologic, psychological, and social development and less to chronologic age.

\section{Molecular pathways linking cancer and aging}

Many of the mechanisms that may account for the aging process have also been shown to influence carcinogenesis. In turn, those mechanisms affecting carcinogenesis may influence aging. Indeed, the incidence of cancer is closely linked to age because molecular pathways of aging and cancer are intertwined. ${ }^{12,57,58}$ On the cellular level, aging and carcinogenesis are both believed to be associated with the accumulation of damage, senescence, and disruption of the replicative capacity of a cell.

There are several mechanisms and pathways that suggest that cancer and aging are closely linked. Aging, like many other biological processes, is subject to regulation by genes that reside in pathways that have been conserved during evolution. ${ }^{59}$ For example, the insulin/ IGF-1, mTOR and p53 pathways are among those conserved pathways that impact longevity and aging-related diseases such as cancer. ${ }^{60}$ Other mechanisms, such as oxidative stress, telomere shortening, apoptosis, and various types of activation of tumor suppressor genes may cause a cell to senesce and may be associated with cancer development. ${ }^{61,62}$ Recently, it was established that the major tumor suppressor TP53 interferes with the insulin pathway and that the cancer protective p53 mutation leads to accelerated aging ${ }^{63}$ thus providing a mechanistic link between the insulin pathway, aging, and cancer. Mutations of the TP53 gene and/or altered expression of the 53 protein have been shown to be associated with UCB progression and metastasis. ${ }^{64,65}$ Another mechanism linking aging and cancer is oxidative stress through which the production of reactive oxygen species and free radicals can activate the transcription of genes implicated in inflammatory and other diseaseassociated processes. These may also produce damage of DNA and various protein species associated with aging and malignancy. ${ }^{66}$

Telomeres are repetitive amino acid sequences at the ends of chromosomes that protect against erosion of coding sequences of normal cells and prevent illegal fusion with other chromosome ends. Normal cells undergo a limited number of cell divisions as dictated by the length of telomeres, ${ }^{67}$ since critical shortening of telomeres leads to cell cycle arrest and cellular arrest. The link between telomere length and susceptibility to cancer ${ }^{57,68,69}$ suggest that telomere shortening is an important mechanism predisposing to cancer development. Moreover, the enzyme telomerase has been suggested to promote cancer by adding DNA repeats to the telomeric ends. Indeed, high expression of telomerase in cancer cells is thought to render them immortal. ${ }^{70-72}$

Depending on the specific genetic background of tumor cells, the inhibition of telomerase could induce growth arrest and could be applied in cancer therapy. ${ }^{73}$ Overcoming the cell cycle arrest signals of critically short telomeres has been found to be challenged by cancer cells. ${ }^{74}$ If telomerase is activated, telomere length can be restored, and the otherwise normal stop on proliferation control might be overridden. Thus telomerase activation could be a step toward malignant transformation. ${ }^{75}$ Therefore the regulation of telomere length and the 
telomere length restoring mechanism, such as telomerase activity, are mechanisms that link the molecular pathways of aging and those of cancer. Bladder cancer cells produce telomerase ${ }^{76}$ and regenerate telomeres, ${ }^{77}$ thereby evading cell death. In humans, telomere length has been found to be shorter in UCB patients as compared to control subjects. ${ }^{78}$ Telomeres and telomerase are currently being investigated in the detection and treatment of UCB. ${ }^{79}$

Just as research on aging has advanced our understanding of cancer, the reverse is also true. Molecular pathways that were originally found to be implicated in cancer were shown to be associated with aging mechanisms. For example, epigenetic changes such as DNA methylation influence both aging and cancer by causing genome-wide molecular alterations and silencing of gene expressions. Age-dependent hyper- and hypomethylation may contribute to carcinogenesis by silencing tumor suppressor and/or repair genes or by inducing the expression of oncogenes, respectively.

\section{Age and development of bladder cancer}

Age has been found to be an independent risk factor for the development of UCB..$^{80}$ Various demographic studies have shown that individuals age 65 and older have an 11-fold increase in the incidence of cancer in general and a 15-fold increase in cancer mortality when compared with individuals less than age $65 .{ }^{80}$ Correspondingly, the incidence of UCB is $28.6 \%$ in patients under 65 years and $71.4 \%$ in those over 65 years with a clear increase in those above the age of 50 years. ${ }^{81}$ The incidence of UCB increases from roughly 142 per 100,000 men and 33 per 100,000 women age 65 to 69 years to 296 per 100,000 men and 74 per 100,000 women 85 years old or older.

Several hypothesis-generating studies have reported that the proportion of females with UCB increases with advancing age. In a retrospective review of 576 patients from a single institution, Shi et al. reported that the male/female ratio was 4.1:1, 3.6:1, and 2.3:1 in patients 40 years and younger, $41-59$ years old, and those 60 years or older, respectively. ${ }^{82}$ Similarly, in the US Nurses' Health Study cohort, postmenopausal women were at increased risk for UCB (incidence rate ratio $=1.93,95 \%$ confidence interval: $0.99,3.78$ ) compared with pre-menopausal women. ${ }^{83}$ For postmenopausal women, early age at menopause ( $\leq 45$ years) compared with late age at menopause ( 250 years) was associated with a statistically significant increased risk of UCB (incidence rate ratio $=1.63,95 \%$ confidence interval: $1.20,2.23)$.

Recent data obtained by California Cancer Registry revealed that the peak incidence of UCB is at 85 years. ${ }^{84}$ This age is 20 years after the general retirement age and it implies a longer than usual latent period in carcinogenesis. Moreover, there is a 10 year peak difference between lung/bronchus cancer and UCB, two malignancies that share some of the same carcinogens (i.e., tobacco and industrial exposure). This has been hypothesized as the result of the lungs being the first organs to come into contact with these carcinogens, and the bladder as exposed last and in a more dilute potency. Thus the bladder may require longer exposure for the induction of cellular mutations by carcinogens. 
The relative late presentation of UCB can be hypothesized to be the result of the accumulation of exposures to a variety of carcinogens over time, the main ones being cigarette smoking and occupational exposure to various aromatic amines. In addition, aging may be accompanied by a decreased ability to fully empty the bladder (i.e., voiding inefficiencies), potentially prolonging the contact time for exposure to carcinogens excreted in the urine. Furthermore, because of bothersome voiding symptoms, people may drink less as they get older. Over time, this may increase the urinary concentration of carcinogens to which the elderly are exposed.

Other factors may also play a role. Urothelial enzymes that inactivate carcinogens may deteriorate over time, effectively increasing exposure of the urothelium to active carcinogens. In addition, enzymatic activity may vary between individuals on a genetic basis, compounding the risk that prolonged contact with the urothelium may create. For example, Momose et al. have shown that urinary epidermal growth factor is a promoter of UCB in a heterotopically transplanted rat bladder model. ${ }^{85}$

Further increasing the risk of exposure is the diminishing pulmonary function and the chronic effects of cigarette smoking on the lungs. Their increasing inability to clear themselves of carcinogens that may have been inhaled increases the cumulative amount of carcinogens that are absorbed systemically, with lesser metabolism of these carcinogens by an age-associated decrease in liver and lung function.

Whether expression of host factors and their interaction with environmental factors (as each may contribute to the development of UCB) change as individuals age is unknown. Importantly, there is no evidence to suggest that exposure to a particular carcinogen or the activity of a particular host factor determines the particular form of malignancy that develops. ${ }^{80}$

As with incidence, mortality from UCB is also higher in the elderly. The ratio of cancerspecific mortality to incidence for men and women in the US age 65 to 69 years is $14 \%$ and $18 \%$, respectively, whereas for men and women age 80 to 84 it is $30 \%$ and $37 \%$, respectively (SEER, 1973-1997). ${ }^{80}$ There have been several studies on the biological and clinical aggressiveness of UCB in young versus old patients suggesting this correlation, but these have been relatively inconclusive. The higher mortality in the elderly has several possible explanations. In patients under the age of 40 , UCB tend to be well differentiated and behave in a more indolent fashion. ${ }^{86-88}$ While some groups observed lower rates of disease recurrence and progression with better survival in younger patients, ${ }^{82,86-92}$ others have reported that the natural history of UCB in the younger age groups resembles that in older patients. ${ }^{93-97}$ Differences in outcomes between elderly and their younger counterparts may be due to a combination of a relatively more advanced stage at diagnosis (due to social and biologic reasons) and the administration of less aggressive and effective therapies in the elderly. 


\section{Age and treatment outcomes of non-muscle-invasive bladder cancer}

\section{a. Cancer-specific outcomes}

Treatments for non-muscle invasive UCB are generally well tolerated by the elderly. Surgical procedures and the anesthetic support they require are not particularly intrusive or disruptive. Neither creates scenarios where there are major fluid shifts or pressures imposed on the cardiovascular, pulmonary, renal, or liver system.

For UCBs with a low risk proliferative diathesis, disease recurrence and management does not create a life-threatening risk or impact on organ systems. Even when they require repeated endoscopic resection with/without intravesical instillation of chemotherapeutic or immunotherapeutic agents, risks of side effects and complications are low. Most of the agents are not absorbed systemically and therefore do not produce significant systemic effects to which the elderly may be more vulnerable. Moreover, in certain elderly patients whose co-morbid conditions may create an increased risk for anesthesia, treatments for the majority of these tumors can be deferred without increasing risk to the patient since the majority of the tumors themselves are low grade and confined to the mucosa and are therefore of low risk for progression, not threatening survival.

\section{b. Response to Bacille-Calmette Guerin}

Non-muscle-invasive UCB that invades the lamina propria or that is of high grade represents a greater risk for progression and age may be more influential in both the course of the cancer and its treatment outcomes. Treatment for these diatheses with intravesical Bacille Calmette-Guerin (BCG) requires an intact immune response, particularly cell-mediated immunity. In addition, an intact immune response may be needed to maintain a therapeutic effect through continued "booster" or "maintenance" intravesical instillations. Because innate and adaptive immunities deteriorate with age, ${ }^{98}$ elderly patients may be less able to respond to BCG. In a retrospective analysis of 805 patients with multiple or recurrent highgrade Ta, T1, and/or carcinoma in situ, Herr showed that patient age did not affect the initial response to BCG therapy. ${ }^{99}$ However, patients aged 70 to 79 years were less likely to sustain that response and remain free of tumor recurrence during a five-year period. Similarly, Joudi et al. reported that patients older than 80 years had a poor response to BCG plus interferon therapy. ${ }^{100}$ Even after controlling for the effects of tumor stage, grade, tumor size, gender, prior intravesical BCG, BCG maintenance, BCG failure pattern, and primary versus recurrent disease, advanced age was a predictor of treatment efficacy. While these two studies show an impact of age on response to immunotherapy, this effect appears to be small.

In addition, the potential side effects or complications of intravesical BCG may not be as well tolerated in elderly individuals whose vascular, cardiac, immunologic and pulmonary reserve may not withstand instances when intravascular dissemination of the tubercle bacillus produces hypotension, pulmonary compromise, sepsis, and/or cardiovascular collapse. Even more minor complications such as high fevers, increased urinary frequency, discomfort on urination, hematuria and clot retention and the need for repeated catheterization may be problematic for the elderly patient to withstand or tolerate. Some 
studies have shown that BCG is a viable therapeutic option in patients with high risk nonmuscle invasive UCB and concomitant lymphoma, chonic lymphocytic leukemia, treatment with low dose oral steroids, treatment with inhaled steroids, or renal transplant. ${ }^{101,102}$ Advanced age, however, is considered a risk factor for complications in patients receiving BCG therapy ${ }^{103}$ and there are numerous reports of serious complications of BCG therapy in elderly individuals. ${ }^{104-108}$ In a retrospective study of 58 patients, Heiner et al. found that the complication rate of BCG therapy was higher in patients older than 70 years $(48.6 \%$ vs $17.6 \%$ for those younger than 70 years) with the peak incidence occurring with the third dose of BCG therapy. ${ }^{109}$ Interestingly, in this and previous studies, medication that inhibit fibrin clot formation diminished the side effects of BCG therapy but also adversely affected efficacy. ${ }^{109-112}$ Taken together, these data has led some investigators to suggest caution with administration of BCG therapy in the elderly and even avoidance of this therapy in the oldest elderly (80 years and older). ${ }^{109}$

\section{Age and treatment outcomes of muscle-invasive bladder cancer}

When muscle invasive UCB is diagnosed in the elderly, considerations of selective treatments become even more complicated. The standard treatment for muscle-invasive bladder cancer is radical cystectomy. ${ }^{113,114}$ Many also believe that a course of neo-adjuvant chemotherapy may be of benefit in certain patients. ${ }^{115-121}$ Each of these treatments creates substantial challenges to the various organ systems in the body both individually and in aggregate, and potentially even more so for the elderly in whom gradual diminution of physiologic capabilities to withstand the rigors of these treatments has occurred over time. These same events could compromise the capabilities required to respond to these treatments. In addition, decreased physiologic reserve could compromise the recoverability of the different organ systems and of the host as a whole to these treatments. Co-morbid conditions and the fundamental "frailty" that accompany the aging process might also compromise the actual delivery of treatments to their full dosages and capabilities. In addition, potential side effects and complications of treatments might themselves create morbidities and mortality in an already weakened cancer patient with a reduced ability to respond to the additional treatments needed in these situations and fully recover.

\section{a. Efficacy of radical cystectomy}

Radical cystectomy has been firmly established as the best treatment for patients with muscle-invasive or refractory non-muscle invasive UCB. However, most patients with invasive UCB never actually undergo radical cystectomy. ${ }^{122}$ Hollenbeck et al. used the Surveillance Epidemiology and End Results database to identify 13,796 patients with UCB, $24 \%$ if whom were $>80$ years old. ${ }^{123}$ Elderly patients were less likely to be treated with extirpative surgery than their younger counterparts. Nevertheless, after controlling for tumor grade and stage, cystectomy was associated with the greatest risk reduction of death from UCB (HR 0.3 for cancer-specific survival and 0.4 for all cause survival). In another analysis of patients from the SEER database, Prout et al. ${ }^{122}$ reported that only $55 \%$ of those in the 55-59 years age group whose cancers indicated the need for radical cystectomy actually underwent this surgery. Furthermore, the percentage of those treated with radical cystectomy decreased with increasing age of the patient with only approximately $25 \%$ of patients $70-79$ 
years of age undergoing bladder removal. This suggests that radical cystectomy is all too often withheld or delayed in patients who could benefit. Reasons for this are multi-factorial and can only be hypothesized on. They include a delay in diagnosis, the use of nonsurgical alternatives for an inappropriately long period of time, the relative inexperience of many surgeons leading them to avoid performing this procedure, or a perception that many patients simply will not tolerate surgery because of age and/or co-morbidity.

Elderly patients face both clinical and broader institutional barriers to appropriate treatment, are less likely to have their cancer staged, ${ }^{45,124}$ and may receive less aggressive treatment and sub-therapeutic dosing because of co-morbid conditions or perceptions of less physiologic reserve, inability to withstand the more rigorous therapeutic approaches, or greater underlying risk to experience side effects and complications. For example, older UCB patients are less likely to receive extended lymph node dissection and/or adjuvant chemotherapy. ${ }^{92}$ Moreover, older patients may not be referred to comprehensive cancer centers and/or may not be offered participation in clinical trials on account of these perceptions and considerations.

Several investigators have demonstrated a direct correlation between patient age and poor oncologic outcomes after radical cystectomy. ${ }^{91,92,125-127}$ For example, Nielsen et al. found that advanced age was associated with extravesical disease, upstaging from clinical to pathologic stage, and, more importantly, all-cause and cancer-specific mortality in 888 patients treated with radical cystectomy. ${ }^{92}$ Similarly, Clark et al. found that higher age was associated with higher rate of early complications, disease recurrence, and overall mortality in 1,054 cystectomy patients. ${ }^{125}$ Reasons for this could be a change in the biologic potential of the tumor cell or a decrease in the host's defense mechanisms with advancing age, or even a detrimental effect of differences in care patterns in elderly compared to younger patients (i.e., selection for radical cystectomy, delay in radical cystectomy, decreased administration of adjuvant chemotherapy, and/or decreased performance of extended lymphadenectomy). There may be a reluctance to perform radical surgery in older patients with co-morbidities resulting in higher tumor stage when surgery is eventually performed leading to higher cancer-specific mortality. ${ }^{92,122}$

An alternative explanation may be there is a longer delay between diagnosis and definitive treatment in elderly patients resulting in disease progression and worse survival. ${ }^{128-130}$ Yet, another theory to explain the inferior outcome in elderly patients is the suboptimal use of lymphadenectomy and adjuvant chemotherapy. Indeed, elderly UCB patients are less likely to receive postoperative chemotherapy in the presence of advanced disease stage. ${ }^{92,125}$ This may be partially due to the frailty and presence of significant comorbidities such as impaired renal function and cardiac disease (see "physiologic changes that occur with aging" section). The risk/benefit ratio is differently weighted in the elderly compared to younger patients. The trade-off between life years gained versus quality of life may be different from the perspective of elderly compared to younger patients.

The host response may also play a critical role in the differential cancer-specific mortality rates between young and elderly patients treated with radical cystectomy for UCB. Miller et al., for example, showed that the Charlson Index score is a strong predictor of increased risk 
of extravesical disease and cancer-specific mortality. ${ }^{131}$ Koppie et al. found that ageadjusted Charlson comorbidity score is associated with treatment decisions and clinical outcomes. Weizer et al. found that management with cystectomy yielded the best survival chances in patients with non-metastatic, muscle-invasive UCB who are older than 70 years. ${ }^{132}$ In a multivariate analysis that adjusted for the effects of treatment type, weight loss, and caregiver status, the Karnofsky performance status was the only predictor of overall survival. Taken together the data from these studies further support that the majority of elderly patients are able to undergo definitive treatment with $\mathrm{RC}$ and that in elderly patients with a good performance status, RC offers the best disease control and survival.

\section{b. Complications of radical cystectomy}

Radical cystectomy and urinary diversion present individual challenges to any patient, especially to the elderly. The procedures themselves are lengthy, require the relative health and reserves of each organ system to recover fully and rapidly, and incorporate an often complex reconstruction of an urinary reservoir or conduit to assume the function of the bladder in storing and eliminating urine. These procedures result in a peri-operative morbidity of 30-60\%, even at major referral centers with experience. ${ }^{113,133-135}$ Each of these procedures challenges the patient not only in their initial recovery but over the longterm. These considerations may be particularly significant in the elderly individual already weakened both by an aggressive cancer and compromised by deterioration of multiple organ systems. Fortunately, both morbidity and mortality rates have declined dramatically due to significant improvements in peri-operative care. ${ }^{114,134,136}$ For example, in a large single institutional series from the Vanderbilt University, Parekh et al. have reported a mortality rate of only $1 \%$ despite the inclusion of many patients with significant comorbidities. ${ }^{137} \mathrm{In}$ fact, only approximately $5 \%$ of patients referred for consideration of radical cystectomy are considered ineligible for the procedure because of co-morbidities. ${ }^{138-140}$ Farnham et al. reported a low mortality rate even when specifically evaluating patients both older than age 75 years and with significant co-morbidities as measured using the American Society of Anesthesiology (ASA) physical status classification. ${ }^{138}$ Fairey et al. found that age is not associated with 90-day morality or early postoperative complications in a dataset of 314 radical cystectomy patients. ${ }^{141}$ Conversely, in the Health Care Utilization Project involving 13,964 patients who underwent radical cystectomy, Konety et al. showed that increasing age was independently associated with in-hospital mortality after radical cystectomy (OR 1.05, 95\% CI 1.03-1.07). ${ }^{142}$ Similarly, in a report of 2,538 radical cystectomy patients from the NSQIP, Hollenbeck et al. found that increasing age was independently associated with an increased risk of any postoperative complication after radical cystectomy (OR 1.3, 95\%CI 1.2-1.5). ${ }^{143}$ In a review of the data from Memorial Sloan-Kettering Cancer Center, Siegrist et al. found that octogenarians $(117 / 1142,10 \%)$ were more likely to experience a postoperative complication ( $72 \%$ vs $64 \%$ overall, $\mathrm{p}=0.08$ ) than younger patients, with cardiac and neurologic complications more commonly $(\mathrm{p}<0.002) .{ }^{144}$ However, the incidence of major complications ( $17 \%$ for patients $\geq 80$ vs $13 \%<80)$ did not differ significantly between age groups $(\mathrm{p}=0.3)$ despite higher preoperative comorbidity indexes $(\mathrm{p}<0.001)$ in octogenarians. Median length of stay was 1 day longer in octogenarians (10 vs 9 days; $p=0.02$ ). Thirty day mortality was $3.4 \%$ in octogenarians vs $1.2 \%$ in younger pts. There was no significant difference in disease-specific survival compared to younger 
patients; however, octogenarians were more likely to die of causes unrelated to bladder cancer. Reasons for the differences between studies are unknown, but may be related to differences in study populations, definitions of clinical outcomes and study designs. Nonetheless, the data show that chronological age alone is not sufficient to reveal the worse outcomes observed in elderly patients treated with radical cystectomy. More importantly, the cumulative data suggests that chronological age should not preclude definitive surgical therapy.

Unfortunately, alternative approaches (extensive transurethral resection and external radiation therapy in conjunction with systemic chemotherapy) are unlikely to provide a cure and may only temporize an individual's "disease-free" survival without increasing actual survival or "quality of life" survival. ${ }^{123,145}$ Although partial cystectomy has been suggested as another option, up to $65-75 \%$ disease recurrence is seen. ${ }^{146,147}$ Therefore, partial cystectomy is only suitable to treat patients in whom tumors meet strict criteria such as (1) no prior history of bladder cancer, (2) no malignancy (eg, carcinoma in situ or papillary tumors) distant from the known bladder cancer, (3) a solitary muscle-invasive tumor located well away from the ureteral orifices that is amenable to partial cystectomy (ie, 1- to 2-cm of normal bladder around the lesion), and (4) a reasonable expectation that the residual postoperative bladder will have adequate capacity and compliance to ensure functionality. This limits candidates for partial cystectomy to approximately 5 to $10 \%$ of patients needing cystectomy. ${ }^{146,147}$ Finally, partial cystectomy entails a major surgical procedure and may compromise the reservoir capacity of the bladder, adversely affecting a patient's quality of life without offering a credible expectation of cure.

Similarly, radiation therapy has not been proven to be successful in curing patients of muscle-invasive UCB. ${ }^{114,148}$ Notwithstanding earlier reports that suggested some benefit, the majority of patients ultimately succumb even when radiation is combined with systemic chemotherapy. ${ }^{149-151}$ Moreover, concerns regarding quality of life issues overall with this approach may make this a less than optimal choice for patients of any age. ${ }^{152}$

\section{c. Urinary diversion}

Quality of life is an important consideration after radical cystectomy. The differences in body image and urinary, sexual, and social function after radical cystectomy are still unclear. Elderly patients are offered primarily an ileal conduit whereas ileal neobladder are usually reserved for younger and healthier patients. ${ }^{113,133,153}$ Sogani et al. found a nonsignificant trend towards higher complications in 85 elderly patients with ileal neobladder compared to elderly patients with ileal conduit. ${ }^{154}$ Madersbacher et al. found that age is an important determinant for long-term reservoir capacity, nocturia, and continence status in patients with ileal neobladder. ${ }^{155}$ Similarly, Hautmann et al. found that continence status at 5-year follow-up approached $100 \%$ in patients younger than 50 years versus $90 \%$ for those older than 60 years. ${ }^{156}$ One of the explanations for this difference may be the decreasing external urethral sphincter function with age. ${ }^{156}$ Another hypothesis could be that the increased leakage with advancing age is due to the decreased vigilance of aging patients towards this issue, thereby further impairing urethral sensitivity and resulting in an increase 
in incontinence. ${ }^{157}$ Similarly, age is the best predictor of recovery of erectile function after radical cystectomy. 158

The presence of an advanced cancer can itself be deleterious to the host through its effect on the fundamental nutritional status and immunologic response mechanisms that may be integral in an effective recovery both short term and long term. In addition, the lengthy time for surgery and of general anesthesia produces an exposure to medications that may not only alter cognition, which is likely to be decreased with compromised recoverability in the elderly, but may also affect metabolic processes of each organ system through effects on blood pressure, respiratory function, cardiac function, and bowel function. Despite careful preoperative assessment and efforts to support and optimize the function of organ systems before surgery is undertaken, and meticulous and comprehensive intra-operative and postoperative monitoring and support maneuvers for each organ system to enhance recovery and healing, the lengthy and exhaustive challenges that surgery and anesthesia entail, together with the changes in metabolism and compromised nutrition from the catabolism associated with the cancer and from decreased anabolism created by decreased caloric and protein intake pre- and post-operatively, create a significant stress for any patient, and particularly for elderly patients.

\section{Age and chemotherapy}

Adding to the complexity and risk for older individuals is the peri-operative use of systemic chemotherapy Although peri-operative chemotherapy improves cancer-specific survival in patients with muscle-invasive UCB, ${ }^{115-121}$ it can also have a general deleterious effect on various organ systems with potential side effects that delay surgery and from which an older patient may not fully recover. The various systemic agents used may compromise the immune system and its ability to respond to infection, and the cardiac, renal, hepatic and pulmonary function in their ability to respond to various physiologic challenges intraoperatively and in the postoperative recovery period. Furthermore, any pre-existing compromise to these systems through co-morbid conditions or through the physiologic deterioration that has occurred with aging may limit the application of full-dose treatment, thereby limiting the putative benefit offered by chemotherapy administered in conjunction with surgical treatment.

Ongoing treatment for co-morbid conditions such as diabetes, pulmonary disease, and heart disease may also result in various drug interactions when chemotherapy is introduced. Chronic diseases, such as renal or liver disease, may alter the pharmacokinetics and pharmacodynamics of chemotherapeutic agents (see "physiologic changes that occur with aging" section). These changes, as well as alterations in drug absorption, distribution, metabolism, and excretion, may result in greater exposure to toxicities among older cancer patients. ${ }^{159,160}$ Consequently, older adults may be less likely to receive optimal doses of chemotherapy compared with younger patients because of toxicities and complications. ${ }^{92,161,162}$ Treatment trials seldom adjust for individual and/or multi-organ comorbid conditions. ${ }^{160,163,164}$ 
Additional problems may occur when side effects or complications of treatment are encountered. First, the pattern, severity, and management response of older adults to the toxic and adverse effects of treatment have not been well documented. Second, identifying how age influences symptom severity endpoints is essential. Third, even one complication in the elderly can be devastating. This can significantly prolong hospitalization and can influence the likelihood that additional complications may occur. Fourth, each may further compromise the physiologic reserve of an organ system affected directly by the complication or by the treatment itself. Notwithstanding all of these considerations, many have indicated the feasibility of performing radical surgery and administering systemic chemotherapy in older patients and have reported that many patients actually do quite well when selected on the basis of their performance status with good medical control of any comorbid conditions.

Cisplatin-based chemotherapy, the most effective chemotherapy of UCB, is associated with various toxicities such as nephrotoxicity, ototoxicity, neurotoxicity, and vascular toxicity (i.e., cardiovascular, cerebrovascular, thrombotic microangiopathy, and Raynaud's phenomenon). ${ }^{165}$ The probability of these toxicities is increased by an age-related decline in renal function leading to higher half-life of the toxic metabolites of chemotherapeutic regimens. Indeed, Dash et al. found that impaired renal function made $>40 \%$ of patients aged $>70$ years ineligible for cisplatin-based chemotherapy. ${ }^{166}$

Therefore, non-cisplatin-based chemotherapy regimens have become an attractive alternative for elderly patients with advanced UCB, despite their apparently inferior efficacy. Castagneto et al. assessed the efficacy of gemcitabine mono-chemotherapy in 23 unselected elderly with advanced UCB (median age 76 years; range 71-87). ${ }^{167}$ At the end of the therapy, the Comprehensive Geriatric Assessment parameters improved in four cases $(17 \%)$, remained unchanged in 17 cases (74\%) and worsened in two cases (9\%). The overall response rate was $45.5 \%$ (95\% CI 24.3-65.7), median overall survival was 8 months, and median time to progression was 5 months. Treatment was generally well tolerated, with one patient having grade 3 gastrointestinal toxicity and three having grade 4 neutropenia. The authors concluded that gemcitabine mono-chemotherapy was safe and effective, and did not worsen the functional status of elderly patients.

In another study, Bamias et al. evaluated the safety and efficacy of first-line gemcitabine/ carboplatin in 34 patients aged $>70$ years with advanced UCB who were not candidates for cisplatin-based chemotherapy (ECOG performance status $\geq 2$, creatinine clearance $<50$ $\mathrm{ml} / \mathrm{min}$ or co-morbidities precluding cisplatin administration). ${ }^{168}$ Response rate was $24 \%$ (95\% CI 11-41); median progression-free survival was 4.4 months (95\% CI 1.03-7.75) and median overall survival was 9.8 months (95\% CI 4.7-14.9). Patients with no activities of daily living (ADL) or instrumental ADL dependency and no co-morbidities or those with instrumental ADL dependency or one-to-two co-morbidities did better than elderly patients with ADL dependency or more than two co-morbidities.

Careful assessment of co-morbid conditions ${ }^{169}$ and organ function and physiologic reserve and how these factors may lead to suboptimal treatment dosing among older patients warrant further research. Among older cancer patients, losses in physical function and disability are 
associated with losses of functional reserve, which, in the presence of chemotherapy, increase the likelihood that these patients will experience toxic side effects. ${ }^{45,160}$ However, studies are needed to define the tolerance and response to treatment among older patients with various levels of disability, describe how these treatments impact patients' functional reserves and define their ability to recover reasonable levels of functioning after the end of treatment. Finally, the interplays between adequate treatment, organ function, and dose delays, reductions, and stoppages need to be assessed carefully. Such information can help estimate life expectancy and treatment tolerance and ultimately establish a common classification of physical function that may be useful in planning care for older individuals.

It is important to weigh the risks associated with surgery and chemotherapy and the benefits that these can provide in the context of an individual's life expectancy and how these may be influenced by the efficacy of surgery and other treatments on the cancer and the effects of the treatments themselves on the host's fundamental physiologic status, longevity and quality of life. At least $50 \%$ of patients who undergo radical cystectomy for muscle-invasive UCB are likely to have occult metastases which will be clinically expressed in the majority of patients within two years of diagnosis. ${ }^{113-121}$ Unless there is also a palliative intent in performing cystectomy, surgery will by definition not be effective in those who already have metastases but in whom we were unable to detect this situation. Added to this are issues involving quality of life in these patients. Both systemic chemotherapy and radical surgery can significantly compromise quality of life early in their overall course in harboring a cancer, the time when a patient's quality of life is most important to them. Quality of life can be further compromised by the complications that may occur with either systemic chemotherapy or surgery, both of which may compromise the patient's survival even though this effect is difficult to quantify.

Ultimately, distinctions need to be made between providing palliative therapy, particularly when the likelihood of curative therapy is remote, and when the risks, side effects, and potential complications far outweigh the potential benefits that radical surgery and systemic chemotherapy may offer. A palliative approach is not necessarily bad. Individuals are left with a decent quality of life early on. It is only towards the end when their cancer has expressed its metastatic potential that they are likely to suffer the problems associated with metastatic disease and their mortality. In this setting, a patient's "upfront" time may manifest a good quality of life, and such patients may have been made more comfortable in fulfilling their life expectancy with an improved life quality.

In summary, further investigations of non-cisplatin chemotherapy regimens are necessary in the perioperative and metastatic setting for elderly patients. In addition further evaluation of non-cisplatin and cisplatin-based multimodal therapy are necessary before widespread use of current bladder preservation protocols can be recommended. In this context, geriatric assessment tools need to be integrated in the research and clinical management of the elderly to allow assessment of longitudinal changes in functional status and improve outcome prediction. Finally, more clinical trials evaluating novel agents in the elderly with advanced UCB are necessary. 


\section{Conclusions}

Data on aging and increased life expectancy underscore the need for greater attention to the development of cancer in the elderly. The influence and expansion of interest in the concomitant age-associated illness burden of older persons diagnosed with UCB is essential. Urologists and medical oncologists must deal with the concurrent health problems of aged individuals in medical practice, as cancer occurs frequently in the presence of one or more other chronic diseases or health problems. These chronic diseases and conditions can increase the risk for adverse effects from various treatment interventions. Thus, a priority area in UCB management is the integration of concurrent conditions in decision-making regarding early detection, diagnosis, and treatment.

The incidence of bladder cancer increases as individuals age. The type of UCB (low risk versus high risk disease) that is likely to develop has no likely relationship to the age of the patient, to their genetic vulnerabilities or physiologic capabilities, or to the carcinogens to which they may have been exposed.

Evidence from this review suggests that chronological age alone is an inadequate indicator in determining the clinical and behavioral response of older patients to UCB and its treatment. Each age cohort brings a wide range of co-morbid conditions, depressive affects, physical, social, and cognitive limitations and other indicators of frailty and associated indications of organ decrements and geriatric syndromes. It is important to understand how variations in each of these indicators accompany and successively change in older patient cohorts.

The majority of cases of the elderly with UCB are not life threatening. Their treatment is easily tolerated. On the other hand, the diatheses of UCB that present as or progress to advanced disease require more invasive treatments are the types of cancer that create significant problems for older individuals; not only from the cancers themselves but from the treatments that may be required or selected.

Considerations of the physiology of various organ systems and the physiologic reserve of these organ systems need to be carefully evaluated in determining the optimum therapy that can be applied in treating UCB patients without further compromising their quality of life and longevity.

The critical factor for the success of treatment for muscle-invasive UCB in the elderly is patient selection. Elderly patients when selected carefully appear to tolerate and respond well to cancer treatments. ${ }^{170}$ Although evidence is limited, older patients may derive benefit from peri-operative therapies. ${ }^{124}$ The treatment and management decisions for older cancer patients can therefore be guided by treatments for co-morbid conditions, organ function, frailty, and cognitive status. Therefore chronological age alone should not be viewed as a barrier to treatment. ${ }^{92}$

An awareness of the physiologic capabilities of each organ system and all co-morbidities in an individual patient are important in weighing the risks of various treatments vs. their potential but unpredictable benefits. Additionally, an understanding of how the physiologic 
reserve of each organ system may be compromised such that aggressive treatments do not permit full recoverability of function is equally important to assess. Each of these need to be placed in the context of the life-expectancy of an individual patient and the quality of life they may have either with limited treatment of their cancer, but with better outcome overall.

It is obvious that much work remains to be done and that future research must strive to be trans-disciplinary, engaging and fostering collaborative efforts among researchers in the fields of urology, oncology, behavioral medicine, geriatrics, gerontology, and social medicine. We hope that this review will spur future UCB and aging research to help health care professionals provide better cancer-related care for aging and elderly patients with this disease.

\section{Acknowledgments}

SFS is partially sponsored by the National Institute of Health training grant (T32CA082088).

\section{REFERENCES}

1. Centers for Disease Control and Prevention. [December 16, 2008] 2008. Available at www.cdc.gov/ aging.

2. Kent MM, Mather M. What drives US population growth? Population Bull. 2002; 57:1-40.

3. Kinsella, K.; Velkoff, VA. An aging world: 2005 US census bureau, series P95/005-1. US Government Printing Office; Wahsington, DC: 2005.

4. [November 10, 2008] (www.census.gov) UBoCw

5. Yancik R, Ries LA. Cancer in older persons: an international issue in an aging world. Semin Oncol. 2004; 31:128-36. [PubMed: 15112144]

6. Yancik R, Ries LA. Cancer in older persons. Magnitude of the problem--how do we apply what we know? Cancer. 1994; 74:1995-2003. [PubMed: 8087762]

7. Yancik R, Ries LA. Aging and cancer in America. Demographic and epidemiologic perspectives. Hematol Oncol Clin North Am. 2000; 14:17-23. [PubMed: 10680069]

8. Edwards BK, Howe HL, Ries LA, et al. Annual report to the nation on the status of cancer, 1973-1999, featuring implications of age and aging on U.S. cancer burden. Cancer. 2002; 94:276692. [PubMed: 12173348]

9. Hewitt M, Rowland JH, Yancik R. Cancer survivors in the United States: age, health, and disability. J Gerontol A Biol Sci Med Sci. 2003; 58:82-91. [PubMed: 12560417]

10. Edwards, BK.; Eisner, MP.; Kosary, CL. SEER cancer statistics review, 1975-2002. National Cancer Insitute; Bethesda, MD: 2005. http://seer.cancer.gov/csr/1975_2002/

11. Boss GR, Seegmiller JE. Age-related physiological changes and their clinical significance. West J Med. 1981; 135:434-40. [PubMed: 7336713]

12. Campisi J. Aging and cancer cell biology, 2008. Aging Cell. 2008; 7:281-4. [PubMed: 18331618]

13. Shariat SF, Karam JA, Lerner SP. Molecular markers in bladder cancer. Curr Opin Urol. 2008; 18:1-8. [PubMed: 18090481]

14. Ehdaie B, Theodorescu D. Predicting tumor outcomes in urothelial bladder carcinoma: turning pathways into clinical biomarkers of prognosis. Expert Rev Anticancer Ther. 2008; 8:1103-10. [PubMed: 18588455]

15. Wu XR. Urothelial tumorigenesis: a tale of divergent pathways. Nat Rev Cancer. 2005; 5:713-25. [PubMed: 16110317]

16. Miller CA. Medicate with caution to prevent problems in frail elders. Geriatr Nurs. 2000; $21: 108-$ 9. [PubMed: 10769338]

17. Hurria, A.; Muss, HB.; Cohen, HJ. Cancer and Aging (Chapter 75). In: Kufe, DW., et al., editors. Cancer Medicine. B.C.Decker; Hamilton: 2003. 
18. Edwards BK, Brown ML, Wingo PA, et al. Annual report to the nation on the status of cancer, 1975-2002, featuring population-based trends in cancer treatment. J Natl Cancer Inst. 2005; 97:1407-27. [PubMed: 16204691]

19. Sawhney R, Sehl M, Naeim A. Physiologic aspects of aging: impact on cancer management and decision making, part I. Cancer J. 2005; 11:449-60. [PubMed: 16393479]

20. Sehl M, Sawhney R, Naeim A. Physiologic aspects of aging: impact on cancer management and decision making, part II. Cancer J. 2005; 11:461-73. [PubMed: 16393480]

21. Reuben DB, Rubenstein LV, Hirsch SH, et al. Value of functional status as a predictor of mortality: results of a prospective study. Am J Med. 1992; 93:663-9. [PubMed: 1466363]

22. [December 14, 2008] Statistics. NCfH: Monitoring the Nation's Health. Trends in Health and Aging. (http//www.cdc.gov/nchs/agingact.thm).

23. Dewys WD, Begg C, Lavin PT, et al. Prognostic effect of weight loss prior to chemotherapy in cancer patients. Eastern Cooperative Oncology Group. Am J Med. 1980; 69:491-7. [PubMed: 7424938]

24. Newman AB, Yanez D, Harris T, et al. Weight change in old age and its association with mortality. J Am Geriatr Soc. 2001; 49:1309-18. [PubMed: 11890489]

25. Pedelty L, Gorelick PB. Management of hypertension and cerebrovascular disease in the elderly. Am J Med. 2008; 121:S23-31. [PubMed: 18638616]

26. Baruch L. Hypertension and the elderly: more than just blood pressure control. J Clin Hypertens (Greenwich). 2004; 6:249-55. [PubMed: 15133407]

27. Sharma G, Goodwin J. Effect of aging on respiratory system physiology and immunology. Clin Interv Aging. 2006; 1:253-60. [PubMed: 18046878]

28. Bhagra S, Nippoldt TB, Nair KS. Dehydroepiandrosterone in adrenal insufficiency and ageing. Curr Opin Endocrinol Diabetes Obes. 2008; 15:239-43. [PubMed: 18438171]

29. Raynor MC, Carson CC, Pearson MD, et al. Androgen deficiency in the aging male: a guide to diagnosis and testosterone replacement therapy. Can J Urol. 2007; 14(Suppl 1):63-8. [PubMed: 18163948]

30. Nass R, Johansson G, Christiansen JS, et al. The aging population - Is there a role for endocrine interventions? Growth Horm IGF Res. 2008

31. Pardon MC, Rattray I. What do we know about the long-term consequences of stress on ageing and the progression of age-related neurodegenerative disorders? Neurosci Biobehav Rev. 2008; 32:1103-20. [PubMed: 18436304]

32. Cherubini A, Lowenthal DT, Paran E, et al. Hypertension and cognitive function in the elderly. Am J Ther. 2007; 14:533-54. [PubMed: 18090879]

33. Ferrucci L, Guralnik JM, Salive ME, et al. Cognitive impairment and risk of stroke in the older population. J Am Geriatr Soc. 1996; 44:237-41. [PubMed: 8600190]

34. Extermann M, Hurria A. Comprehensive geriatric assessment for older patients with cancer. J Clin Oncol. 2007; 25:1824-31. [PubMed: 17488980]

35. Fulop T, Larbi A, Hirokawa K, et al. Immunosupportive therapies in aging. Clin Interv Aging. 2007; 2:33-54. [PubMed: 18044074]

36. Wu D, Meydani SN. Age-associated changes in immune and inflammatory responses: impact of vitamin E intervention. J Leukoc Biol. 2008; 84:900-14. [PubMed: 18596135]

37. Kumar R, Burns EA. Age-related decline in immunity: implications for vaccine responsiveness. Expert Rev Vaccines. 2008; 7:467-79. [PubMed: 18444893]

38. Weinberger B, Herndler-Brandstetter D, Schwanninger A, et al. Biology of immune responses to vaccines in elderly persons. Clin Infect Dis. 2008; 46:1078-84. [PubMed: 18444828]

39. Schmucker DL. Age-related changes in liver structure and function: Implications for disease ? Exp Gerontol. 2005; 40:650-9. [PubMed: 16102930]

40. Zeeh J, Platt D. The aging liver: structural and functional changes and their consequences for drug treatment in old age. Gerontology. 2002; 48:121-7. [PubMed: 11961363]

41. Muhlberg W, Platt D. Age-dependent changes of the kidneys: pharmacological implications. Gerontology. 1999; 45:243-53. [PubMed: 10460985] 
42. Turnheim K. When drug therapy gets old: pharmacokinetics and pharmacodynamics in the elderly. Exp Gerontol. 2003; 38:843-53. [PubMed: 12915206]

43. Fehrman-Ekholm I, Skeppholm L. Renal function in the elderly ( $>70$ years old) measured by means of iohexol clearance, serum creatinine, serum urea and estimated clearance. Scand J Urol Nephrol. 2004; 38:73-7. [PubMed: 15204431]

44. Want J, Kamas G, Nguyen TN. Disease management in the frail and elderly population: integration of physicians in the intervention. Dis Manag. 2008; 11:23-8. [PubMed: 18279111]

45. Balducci L. Aging, frailty, and chemotherapy. Cancer Control. 2007; 14:7-12. [PubMed: 17242666]

46. Fried LP, Tangen CM, Walston J, et al. Frailty in older adults: evidence for a phenotype. J Gerontol A Biol Sci Med Sci. 2001; 56:M146-56. [PubMed: 11253156]

47. Walston J, Fried LP. Frailty and the older man. Med Clin North Am. 1999; 83:1173-94. [PubMed: 10503059]

48. Yancik R, Havlik RJ, Wesley MN, et al. Cancer and comorbidity in older patients: a descriptive profile. Ann Epidemiol. 1996; 6:399-412. [PubMed: 8915471]

49. Extermann M. Measurement and impact of comorbidity in older cancer patients. Crit Rev Oncol Hematol. 2000; 35:181-200. [PubMed: 10960800]

50. Satariano WA, Ragland DR. The effect of comorbidity on 3-year survival of women with primary breast cancer. Ann Intern Med. 1994; 120:104-10. [PubMed: 8256968]

51. Welch HG, Albertsen PC, Nease RF, et al. Estimating treatment benefits for the elderly: the effect of competing risks. Ann Intern Med. 1996; 124:577-84. [PubMed: 8597322]

52. Cusack BJ. Pharmacokinetics in older persons. Am J Geriatr Pharmacother. 2004; 2:274-302. [PubMed: 15903286]

53. Brandtstadter J, Renner G. Tenacious goal pursuit and flexible goal adjustment: explication and age-related analysis of assimilative and accommodative strategies of coping. Psychol Aging. 1990; 5:58-67. [PubMed: 2317302]

54. Lockenhoff CE, Carstensen LL. Socioemotional selectivity theory, aging, and health: the increasingly delicate balance between regulating emotions and making tough choices. J Pers. 2004; 72:1395-424. [PubMed: 15509287]

55. Sanderman R, Coyne JC, Ranchor AV. Age: nuisance variable to be eliminated with statistical control or important concern? Patient Educ Couns. 2006; 61:315-6. [PubMed: 16731313]

56. Hurria A, Lachs MS, Cohen HJ, et al. Geriatric assessment for oncologists: rationale and future directions. Crit Rev Oncol Hematol. 2006; 59:211-7. [PubMed: 16806961]

57. DePinho RA. The age of cancer. Nature. 2000; 408:248-54. [PubMed: 11089982]

58. Irminger-Finger I. Science of cancer and aging. J Clin Oncol. 2007; 25:1844-51. [PubMed: 17488982]

59. Schumacher B, Garinis GA, Hoeijmakers JH. Age to survive: DNA damage and aging. Trends Genet. 2008; 24:77-85. [PubMed: 18192065]

60. Feng Z, Hu W, Rajagopal G, et al. The tumor suppressor p53: cancer and aging. Cell Cycle. 2008; 7:842-7. [PubMed: 18414039]

61. Itahana K, Dimri G, Campisi J. Regulation of cellular senescence by p53. Eur J Biochem. 2001; 268:2784-91. [PubMed: 11358493]

62. Campisi J. Analysis of tumor suppressor gene-induced senescence. Methods Mol Biol. 2003; 223:155-72. [PubMed: 12777728]

63. Kirkwood TB. p53 and ageing: too much of a good thing? Bioessays. 2002; 24:577-9. [PubMed: 12111716]

64. Shariat SF, Ashfaq R, Sagalowsky AI, et al. Correlation of cyclin D1 and E1 expression with bladder cancer presence, invasion, progression, and metastasis. Hum Pathol. 2006

65. Esrig D, Elmajian D, Groshen S, et al. Accumulation of nuclear p53 and tumor progression in bladder cancer. N Engl J Med. 1994; 331:1259-64. [PubMed: 7935683]

66. Langen RC, Korn SH, Wouters EF. ROS in the local and systemic pathogenesis of COPD. Free Radic Biol Med. 2003; 35:226-35. [PubMed: 12885585] 
67. Allsopp RC, Chang E, Kashefi-Aazam M, et al. Telomere shortening is associated with cell division in vitro and in vivo. Exp Cell Res. 1995; 220:194-200. [PubMed: 7664836]

68. Metcalfe JA, Parkhill J, Campbell L, et al. Accelerated telomere shortening in ataxia telangiectasia. Nat Genet. 1996; 13:350-3. [PubMed: 8673136]

69. Deng Y, Chan SS, Chang S. Telomere dysfunction and tumour suppression: the senescence connection. Nat Rev Cancer. 2008; 8:450-8. [PubMed: 18500246]

70. Artandi SE, Alson S, Tietze MK, et al. Constitutive telomerase expression promotes mammary carcinomas in aging mice. Proc Natl Acad Sci U S A. 2002; 99:8191-6. [PubMed: 12034875]

71. Artandi SE, DePinho RA. Mice without telomerase: what can they teach us about human cancer? Nat Med. 2000; 6:852-5. [PubMed: 10932211]

72. de Lange T, DePinho RA. Unlimited mileage from telomerase? Science. 1999; 283:947-9. [PubMed: 10075559]

73. Cunningham AP, Love WK, Zhang RW, et al. Telomerase inhibition in cancer therapeutics: molecular-based approaches. Curr Med Chem. 2006; 13:2875-88. [PubMed: 17073634]

74. Campisi J, Kim SH, Lim CS, et al. Cellular senescence, cancer and aging: the telomere connection. Exp Gerontol. 2001; 36:1619-37. [PubMed: 11672984]

75. Opitz OG. Telomeres, telomerase and malignant transformation. Curr Mol Med. 2005; 5:219-26. [PubMed: 15974876]

76. Ito H, Kyo S, Kanaya T, et al. Expression of human telomerase subunits and correlation with telomerase activity in urothelial cancer. Clin Cancer Res. 1998; 4:1603-8. [PubMed: 9676833]

77. Kim NW, Piatyszek MA, Prowse KR, et al. Specific association of human telomerase activity with immortal cells and cancer. Science. 1994; 266:2011-2015. [PubMed: 7605428]

78. Wu X, Amos CI, Zhu Y, et al. Telomere dysfunction: a potential cancer predisposition factor. J Natl Cancer Inst. 2003; 95:1211-8. [PubMed: 12928346]

79. Herman MP, Svatek RS, Lotan Y, et al. Urine-based biomarkers for the early detection and surveillance of non-muscle invasive bladder cancer. Minerva Urol Nefrol. 2008; 60:217-35. [PubMed: 18923359]

80. Messing, EM. Campbell-Walsh Urology. Ninth Edition. Saunders Elsevier; 2008. Urothelial tumors of the bladder (Chapter 75).; p. 2407-2446.

81. Jemal A, Siegel R, Ward E, et al. Cancer statistics, 2008. CA Cancer J Clin. 2008; 58:71-96. [PubMed: 18287387]

82. Shi B, Zhang K, Zhang J, et al. Relationship between patient age and superficial transitional cell carcinoma characteristics. Urology. 2008; 71:1186-90. [PubMed: 18372010]

83. McGrath M, Michaud DS, De Vivo I. Hormonal and reproductive factors and the risk of bladder cancer in women. Am J Epidemiol. 2006; 163:236-44. [PubMed: 16319290]

84. Schultzel M, Saltzstein SL, Downs TM, et al. Late age (85 years or older) peak incidence of bladder cancer. J Urol. 2008; 179:1302-5. discussion 1305-6. [PubMed: 18289593]

85. Momose H, Kakinuma H, Shariff SY, et al. Tumor-promoting effect of urinary epidermal growth factor in rat urinary bladder carcinogenesis. Cancer Res. 1991; 51:5487-90. [PubMed: 1913668]

86. Benson RC Jr. Tomera KM, Kelalis PP. Transitional cell carcinoma of the bladder in children and adolescents. J Urol. 1983; 130:54-5. [PubMed: 6864914]

87. Fitzpatrick JM, Reda M. Bladder carcinoma in patients 40 years old or less. J Urol. 1986; 135:534. [PubMed: 3941469]

88. Linn JF, Sesterhenn I, Mostofi FK, et al. The molecular characteristics of bladder cancer in young patients. J Urol. 1998; 159:1493-6. [PubMed: 9554340]

89. Madgar I, Goldwasser B, Nativ O, et al. Long-term followup of patients less than 30 years old with transitional cell carcinoma of bladder. J Urol. 1988; 139:933-4. [PubMed: 3361666]

90. Witjes JA, Debruyne FM. Bladder carcinoma in patients less than 40 years of age. Urol Int. 1989; 44:81-3. [PubMed: 2728130]

91. Resorlu B, Beduk Y, Baltaci S, et al. The prognostic significance of advanced age in patients with bladder cancer treated with radical cystectomy. BJU Int. 2008 
92. Nielsen ME, Shariat SF, Karakiewicz PI, et al. Advanced age is associated with poorer bladder cancer-specific survival in patients treated with radical cystectomy. Eur Urol. 2007; 51:699-706. discussion 706-8. [PubMed: 17113703]

93. Johnson DE, Hillis S. Carcinoma of the bladder in patients less than 40 years old. J Urol. 1978; 120:172-3. [PubMed: 671625]

94. Kurz KR, Pitts WR, Vaughan ED Jr. The natural history of patients less than 40 years old with bladder tumors. J Urol. 1987; 137:395-7. [PubMed: 3820365]

95. Kutarski PW, Padwell A. Transitional cell carcinoma of the bladder in young adults. Br J Urol. 1993; 72:749-55. [PubMed: 8281408]

96. Wan J, Grossman HB. Bladder carcinoma in patients age 40 years or younger. Cancer. 1989; 64:178-81. [PubMed: 2731112]

97. Yossepowitch O, Dalbagni G. Transitional cell carcinoma of the bladder in young adults: presentation, natural history and outcome. J Urol. 2002; 168:61-6. [PubMed: 12050493]

98. Solana R, Pawelec G, Tarazona R. Aging and innate immunity. Immunity. 2006; 24:491-4. [PubMed: 16713963]

99. Herr HW. Age and outcome of superficial bladder cancer treated with bacille Calmette-Guerin therapy. Urology. 2007; 70:65-8. [PubMed: 17656210]

100. Joudi FN, Smith BJ, O'Donnell MA, et al. The impact of age on the response of patients with superficial bladder cancer to intravesical immunotherapy. J Urol. 2006; 175:1634-9. discussion 1639-40. [PubMed: 16600718]

101. Palou J, Angerri O, Segarra J, et al. Intravesical bacillus Calmette-Guerin for the treatment of superficial bladder cancer in renal transplant patients. Transplantation. 2003; 76:1514-6. [PubMed: 14657696]

102. Yossepowitch O, Eggener SE, Bochner BH, et al. Safety and efficacy of intravesical bacillus Calmette-Guerin instillations in steroid treated and immunocompromised patients. J Urol. 2006; 176:482-5. [PubMed: 16813873]

103. Malkowicz, SB. Campbell's Urology. Eigth Edition. Saunders Elsevier; 2002. Management of superficial bladder cancer.; p. 2789-92.

104. Gonzalez JA, Marcol BR, Wolf MC. Complications of intravesical bacillus Calmette-Guerin: a case report. J Urol. 1992; 148:1892-3. [PubMed: 1433632]

105. Leebeek FW, Ouwendijk RJ, Kolk AH, et al. Granulomatous hepatitis caused by Bacillus Calmette-Guerin (BCG) infection after BCG bladder instillation. Gut. 1996; 38:616-8. [PubMed: 8707098]

106. Marans HY, Bekirov HM. Granulomatous hepatitis following intravesical bacillus CalmetteGuerin therapy for bladder carcinoma. J Urol. 1987; 137:111-2. [PubMed: 3795348]

107. Orikasa K, Namima T, Ota S, et al. Acute eosinophilic pneumonia associated with intravesical bacillus Calmette-Guerin therapy of carcinoma in situ of the bladder. Int J Urol. 2003; 10:622-4. [PubMed: 14633091]

108. Rawls WH, Lamm DL, Lowe BA, et al. Fatal sepsis following intravesical bacillus CalmetteGuerin administration for bladder cancer. J Urol. 1990; 144:1328-30. [PubMed: 2231917]

109. Heiner JG, Terris MK. Effect of advanced age on the development of complications from intravesical bacillus Calmette-Guerin therapy. Urol Oncol. 2008; 26:137-40. [PubMed: 18312931]

110. Hudson MA, Brown EJ, Ritchey JK, et al. Modulation of fibronectin-mediated Bacillus CalmetteGuerin attachment to murine bladder mucosa by drugs influencing the coagulation pathways. Cancer Res. 1991; 51:3726-32. [PubMed: 2065329]

111. Hudson MA, Yuan JJ, Catalona WJ, et al. Adverse impact of fibrin clot inhibitors on intravesical bacillus Calmette-Guerin therapy for superficial bladder tumors. J Urol. 1990; 144:1362-4. [PubMed: 2231927]

112. P'Ng K B, Walsh MD, Seymour GJ, et al. The adverse effect of fibrin-clot inhibiting drugs on intravesical bacillus Calmette-Guerin efficacy for superficial bladder cancer. Aust N Z J Surg. 1993; 63:127-30. [PubMed: 8297300]

113. Stein JP, Lieskovsky G, Cote R, et al. Radical cystectomy in the treatment of invasive bladder cancer: long-term results in 1,054 patients. J Clin Oncol. 2001; 19:666-75. [PubMed: 11157016] 
114. Shariat SF, Karakiewicz PI, Palapattu GS, et al. Outcomes of radical cystectomy for transitional cell carcinoma of the bladder: a contemporary series from the bladder cancer research consortium. J Urol. 2006; 176:2414-22. [PubMed: 17085118]

115. Grossman HB, Natale RB, Tangen CM, et al. Neoadjuvant chemotherapy plus cystectomy compared with cystectomy alone for locally advanced bladder cancer. N Engl J Med. 2003; 349:859-66. [PubMed: 12944571]

116. von der Maase H, Sengelov L, Roberts JT, et al. Long-term survival results of a randomized trial comparing gemcitabine plus cisplatin, with methotrexate, vinblastine, doxorubicin, plus cisplatin in patients with bladder cancer. J Clin Oncol. 2005; 23:4602-8. [PubMed: 16034041]

117. Adjuvant chemotherapy in invasive bladder cancer: a systematic review and meta-analysis of individual patient data Advanced Bladder Cancer (ABC) Meta-analysis Collaboration. Eur Urol. 2005; 48:189-199. discussion 199-201. [PubMed: 15939530]

118. Neoadjuvant chemotherapy in invasive bladder cancer: update of a systematic review and metaanalysis of individual patient data advanced bladder cancer (ABC) meta-analysis collaboration. Eur Urol. 2005; 48:202-5. discussion 205-6. [PubMed: 15939524]

119. Pectasides D, Pectasides M, Nikolaou M. Adjuvant and neoadjuvant chemotherapy in muscle invasive bladder cancer: literature review. Eur Urol. 2005; 48:60-7. discussion 67-8. [PubMed: 15967253]

120. Schultz PK, Herr HW, Zhang ZF, et al. Neoadjuvant chemotherapy for invasive bladder cancer: prognostic factors for survival of patients treated with M-VAC with 5-year follow-up. J Clin Oncol. 1994; 12:1394-401. [PubMed: 8021730]

121. Sonpavde G, Petrylak DP. Perioperative chemotherapy for bladder cancer. Crit Rev Oncol Hematol. 2006; 57:133-44. [PubMed: 15990329]

122. Prout GR Jr. Wesley MN, Yancik R, et al. Age and comorbidity impact surgical therapy in older bladder carcinoma patients: a population-based study. Cancer. 2005; 104:1638-47. [PubMed: 16130136]

123. Hollenbeck BK, Miller DC, Taub D, et al. Aggressive treatment for bladder cancer is associated with improved overall survival among patients 80 years old or older. Urology. 2004; 64:292-7. [PubMed: 15302481]

124. Muss HB, Biganzoli L, Sargent DJ, et al. Adjuvant therapy in the elderly: making the right decision. J Clin Oncol. 2007; 25:1870-5. [PubMed: 17488985]

125. Clark PE, Stein JP, Groshen SG, et al. Radical cystectomy in the elderly: comparison of clincal outcomes between younger and older patients. Cancer. 2005; 104:36-43. [PubMed: 15912515]

126. Cai T, Bartoletti R, Nielsen Matthew E. Shariat Shahrokh F. Karakiewicz Pierre I. et al. Advanced age is associated with poorer bladder cancer-specific survival in patients treated with radical cystectomy. Eur urol. 2007; 51:699-708. Eur Urol 52:611-2, 2007. [PubMed: 17113703]

127. Thrasher JB, Frazier HA, Robertson JE, et al. Clinical variables which serve as predictors of cancer-specific survival among patients treated with radical cystectomy for transitional cell carcinoma of the bladder and prostate. Cancer. 1994; 73:1708-1715. [PubMed: 8156499]

128. Nielsen ME, Palapattu GS, Karakiewicz PI, et al. A delay in radical cystectomy of $>3$ months is not associated with a worse clinical outcome. BJU Int. 2007; 100:1015-20. [PubMed: 17784888]

129. Chang SS, Hassan JM, Cookson MS, et al. Delaying radical cystectomy for muscle invasive bladder cancer results in worse pathological stage. J Urol. 2003; 170:1085-7. [PubMed: 14501697]

130. Sanchez-Ortiz RF, Huang WC, Mick R, et al. An interval longer than 12 weeks between the diagnosis of muscle invasion and cystectomy is associated with worse outcome in bladder carcinoma. J Urol. 2003; 169:110-5. discussion 115. [PubMed: 12478115]

131. Miller DC, Taub DA, Dunn RL, et al. The impact of co-morbid disease on cancer control and survival following radical cystectomy. J Urol. 2003; 169:105-9. [PubMed: 12478114]

132. Weizer AZ, Joshi D, Daignault S, et al. Performance status is a predictor of overall survival of elderly patients with muscle invasive bladder cancer. J Urol. 2007; 177:1287-93. [PubMed: 17382715] 
133. Madersbacher S, Hochreiter W, Burkhard F, et al. Radical cystectomy for bladder cancer today--a homogeneous series without neoadjuvant therapy. J Clin Oncol. 2003; 21:690-6. [PubMed: 12586807]

134. Shabsigh A, Korets R, Vora KC, et al. Defining Early Morbidity of Radical Cystectomy for Patients with Bladder Cancer Using a Standardized Reporting Methodology. Eur Urol. 2008

135. Donat SM, Shabsigh A, Savage C, et al. Potential Impact of Postoperative Early Complications on the Timing of Adjuvant Chemotherapy in Patients Undergoing Radical Cystectomy: A HighVolume Tertiary Cancer Center Experience. Eur Urol. 2008

136. Rosario DJ, Becker M, Anderson JB. The changing pattern of mortality and morbidity from radical cystectomy. BJU Int. 2000; 85:427-30. [PubMed: 10691819]

137. Parekh DJ, Gilbert WB, Koch MO, et al. Continent urinary reconstruction versus ileal conduit: a contemporary single-institution comparison of perioperative morbidity and mortality. Urology. 2000; 55:852-5. [PubMed: 10840090]

138. Farnham SB, Cookson MS, Alberts G, et al. Benefit of radical cystectomy in the elderly patient with significant co-morbidities. Urol Oncol. 2004; 22:178-81. [PubMed: 15271311]

139. Figueroa AJ, Stein JP, Dickinson M, et al. Radical cystectomy for elderly patients with bladder carcinoma: an updated experience with 404 patients. Cancer. 1998; 83:141-7. [PubMed: 9655304]

140. Parekh DJ, Clark T, O'Connor J, et al. Orthotopic neobladder following radical cystectomy in patients with high perioperative risk and co-morbid medical conditions. J Urol. 2002; 168:24546. [PubMed: 12441938]

141. Fairey A, Chetner M, Metcalfe J, et al. Associations among age, comorbidity and clinical outcomes after radical cystectomy: results from the Alberta Urology Institute radical cystectomy database. J Urol. 2008; 180:128-34. discussion 134. [PubMed: 18485375]

142. Konety BR, Dhawan V, Allareddy V, et al. Impact of hospital and surgeon volume on in-hospital mortality from radical cystectomy: data from the health care utilization project. J Urol. 2005; 173:1695-700. [PubMed: 15821560]

143. Hollenbeck BK, Miller DC, Taub D, et al. Identifying risk factors for potentially avoidable complications following radical cystectomy. J Urol. 2005; 174:1231-7. discussion 1237. [PubMed: 16145376]

144. Siegrist TC, Savage CJ, Cronin AM, et al. Radical cystectomy (RC) in octogenarians: does morbidity outweigh the potential survival benefits? J Urol. 2009; 181:633.

145. Herr HW. Transurethral resection of muscle-invasive bladder cancer: 10-year outcome. J Clin Oncol. 2001; 19:89-93. [PubMed: 11134199]

146. Kassouf W, Swanson D, Kamat AM, et al. Partial cystectomy for muscle invasive urothelial carcinoma of the bladder: a contemporary review of the M. D. Anderson Cancer Center experience. J Urol. 2006; 175:2058-62. [PubMed: 16697803]

147. Holzbeierlein JM, Lopez-Corona E, Bochner BH, et al. Partial cystectomy: a contemporary review of the Memorial Sloan-Kettering Cancer Center experience and recommendations for patient selection. J Urol. 2004; 172:878-81. [PubMed: 15310988]

148. Shelley M, Barber J, Wilt T, et al. Surgery verus radiotherapy for muscle invasive bladder cancer. The Cochrane Database of Systematic Reviews. 2001

149. Shipley WU, Zietman AL, Kaufman DS, et al. Selective bladder preservation by trimodality therapy for patients with muscularis propria-invasive bladder cancer and who are cystectomy candidates--the Massachusetts General Hospital and Radiation Therapy Oncology Group experiences. Semin Radiat Oncol. 2005; 15:36-41. [PubMed: 15662605]

150. Zietman AL, Sacco D, Skowronski U, et al. Organ conservation in invasive bladder cancer by transurethral resection, chemotherapy and radiation: results of a urodynamic and quality of life study on long-term survivors. J Urol. 2003; 170:1772-6. [PubMed: 14532773]

151. Kachnic LA, Kaufman DS, Heney NM, et al. Bladder preservation by combined modality therapy for invasive bladder cancer. J Clin Oncol. 1997; 15:1022-9. [PubMed: 9060542]

152. Montie JE. Against bladder sparing: surgery. J Urol. 1999; 162:452-5. discussion 455-7. [PubMed: 10411055] 
153. Stroumbakis N, Herr HW, Cookson MS, et al. Radical cystectomy in the octogenarian. J Urol. 1997; 158:2113-7. [PubMed: 9366325]

154. Sogni F, Brausi M, Frea B, et al. Morbidity and quality of life in elderly patients receiving ileal conduit or orthotopic neobladder after radical cystectomy for invasive bladder cancer. Urology. 2008; 71:919-23. [PubMed: 18355900]

155. Madersbacher S, Mohrle K, Burkhard F, et al. Long-term voiding pattern of patients with ileal orthotopic bladder substitutes. J Urol. 2002; 167:2052-7. [PubMed: 11956437]

156. Hautmann RE, Miller K, Steiner U, et al. The ileal neobladder: 6 years of experience with more than 200 patients. J Urol. 1993; 150:40-5. [PubMed: 8510272]

157. Hugonnet CL, Danuser H, Springer JP, et al. Decreased sensitivity in the membranous urethra after orthotopic ileal bladder substitute. J Urol. 1999; 161:418-21. [PubMed: 9915416]

158. Kessler TM, Burkhard FC, Perimenis P, et al. Attempted nerve sparing surgery and age have a significant effect on urinary continence and erectile function after radical cystoprostatectomy and ileal orthotopic bladder substitution. J Urol. 2004; 172:1323-7. [PubMed: 15371833]

159. Cohen HJ. The cancer aging interface: a research agenda. J Clin Oncol. 2007; 25:1945-8. [PubMed: 17488995]

160. Lichtman SM, Wildiers H, Chatelut E, et al. International Society of Geriatric Oncology Chemotherapy Taskforce: evaluation of chemotherapy in older patients--an analysis of the medical literature. J Clin Oncol. 2007; 25:1832-43. [PubMed: 17488981]

161. Surbone A, Kagawa-Singer M, Terret C, et al. The illness trajectory of elderly cancer patients across cultures: SIOG position paper. Ann Oncol. 2007; 18:633-8. [PubMed: 17028242]

162. Terret C, Zulian G, Droz JP. Statements on the interdependence between the oncologist and the geriatrician in geriatric oncology. Crit Rev Oncol Hematol. 2004; 52:127-33. [PubMed: 15501077]

163. Terret C, Zulian GB, Naiem A, et al. Multidisciplinary approach to the geriatric oncology patient. J Clin Oncol. 2007; 25:1876-81. [PubMed: 17488986]

164. Extermann M, Aapro M, Bernabei R, et al. Use of comprehensive geriatric assessment in older cancer patients: recommendations from the task force on CGA of the International Society of Geriatric Oncology (SIOG). Crit Rev Oncol Hematol. 2005; 55:241-52. [PubMed: 16084735]

165. Li SH, Chen WH, Tang Y, et al. Incidence of ischemic stroke post-chemotherapy: a retrospective review of 10,963 patients. Clin Neurol Neurosurg. 2006; 108:150-6. [PubMed: 16412836]

166. Dash A, Galsky MD, Vickers AJ, et al. Impact of renal impairment on eligibility for adjuvant cisplatin-based chemotherapy in patients with urothelial carcinoma of the bladder. Cancer. 2006; 107:506-13. [PubMed: 16773629]

167. Castagneto B, Zai S, Marenco D, et al. Single-agent gemcitabine in previously untreated elderly patients with advanced bladder carcinoma: response to treatment and correlation with the comprehensive geriatric assessment. Oncology. 2004; 67:27-32. [PubMed: 15459492]

168. Bamias A, Lainakis G, Kastritis E, et al. Biweekly carboplatin/gemcitabine in patients with advanced urothelial cancer who are unfit for cisplatin-based chemotherapy: report of efficacy, quality of life and geriatric assessment. Oncology. 2007; 73:290-7. [PubMed: 18477854]

169. Morrison VA, Picozzi V, Scott S, et al. The impact of age on delivered dose intensity and hospitalizations for febrile neutropenia in patients with intermediate-grade non-Hodgkin's lymphoma receiving initial CHOP chemotherapy: a risk factor analysis. Clin Lymphoma. 2001; 2:47-56. [PubMed: 11707870]

170. Kemeny MM. Surgery in older patients. Semin Oncol. 2004; 31:175-84. [PubMed: 15112148] 